\title{
Construir com o Outro: dinâmica do FóRUM EBCIB
}

\author{
Build with Others: dynamics FORUM EBCIB
}

\author{
Francisco das Chagas de Souza \\ Doutor em Educação pela Universidade Metodista de Piracicaba - UNIMEP. \\ Docente do Departamento de Ciência da Informação e do Programa de Pós-Graduação em Ciência da \\ Informação da Universidade Federal de Santa Catarina - UFSC. \\ E-mail: chagas.cin83@yahoo.com
}

\begin{abstract}
Resumo
Expõe um breve panorama das condições em que se desenvolvem ações próprias dos profissionais bibliotecários, dos investigadores envolvidos na produção e difusão do conhecimento de ciência da informação, biblioteconomia e educação nesses campos e dos representantes do movimento profissional e científico organizados em entidades formais. Demonstra a existência de um contexto que aponta para um enredamento frágil do processo interacional vivido por essas entidades entre si, podendo suscitar uma discussão de perfil ético. A partir do quadro apresentado, traz à discussão o esforço desenvolvido, desde o ano de 2009, com o envolvimento da ABECIN, ANCIB, CFB e FEBAB, na construção de um Fórum de discussão multiinstitucional constituído por essas organizações ou entidades gestoras dos interesses de profissionais, cuja finalidade seria fortalecerem-se mutuamente, nesse espaço, em suas ações relativas à prática e à orientação política e profissional de bibliotecários e cientistas da informação atuantes no Brasil.
\end{abstract}

Palavras-chave: Política profissional; movimento associativo; solidariedade.

\begin{abstract}
It presents a brief overview of the conditions in which they develop own shares of librarians, researchers involved in the production and dissemination of knowledge of information science, library science and education in these fields and representatives of professional and scientific movement organized into formal entities. Demonstrates the existence of a context that points to a fragile entanglement of the interaction process experienced by these entities each other and can elicit a discussion of ethical profile. From the picture presented, moots the effort, since the year 2009, with the involvement of ABECIN, ANCIB, CFB and FEBAB, the construction of a multi-institutional forum discussion consisting of these organizations or managing bodies of interests professionals whose purpose would be to strengthen one another in this space, in their actions relating to the practice and policy and guidance for librarians and information scientists active in Brazil.
\end{abstract}

Keywords: Professional politics; associative movement; solidarity. 


\section{Introdução}

Há diferentes perspectivas que podem escolher-se em distintos momentos com o propósito de construir estratégias de ação destinadas a estimular um processo de debate em torno do alcance de metas que podem reconfigurar, como atividade contínua, as iniciativas coletivas.

Sob essa perspectiva, manifestam-se alguns vieses nas ações desenvolvidas pelos profissionais atuantes nas aplicações práticas; pelos investigadores envolvidos na produção do conhecimento e de seu uso para fins educacionais; pelos profissionais envolvidos na ação política; pelos autores evidenciados pelo processo de comunicação científica. Esses vieses decorrem de circunstâncias cotidianas que se manifestam no mundo da vida e, por existirem, apontariam para um enredamento frágil dos nódulos institucionais em quaisquer campos profissionais e científicos quanto à interação que desenvolvem.

Trata-se, certamente, de fenômenos vividos por todos os grupos humanos em sociedade, e mais especificamente, por aqueles perfilados em torno de objetos e objetivos ocupacionais, e isso tende a contribuir para a produção de virtual esgarçamento em suas articulações institucionais.

No presente artigo tem-se como objetivo expor o contexto, as condições e as ações desenvolvidas visando à construção de um ambiente multi-institucional constituído pelas organizações ou entidades gestoras dos interesses de profissionais envolvidos com a execução de ações relativas à prática e à orientação política e profissional de bibliotecários e cientistas da informação atuantes no Brasil.

\section{Um cenário das ações em foco}

A noção do que se designa como ação tem distinta carga semântica, decorrente de diversos olhares filosóficos, predominando o sentido dinâmico de participação intencionada no mundo vivido (SCHUTZ; LUCKMANN, 2003). Agir nesse caso é promover movimento que tende a responder à ideia de construção de soluções ou quase soluções em resposta aos desejos, interesses e necessidades de grupos sociais ou ocupacionais, vivendo num dado espaço e tempo. Em outros termos, trata-se de um agir conscientemente com sentido político, ou melhor, enxergando a relevância da compreensão de que a sociedade é constituída pela 
demarcação de espaços de poder, multi coordenados e conduzindo-a em uma interminável construção.

Por todo o século XX foi se constituindo no Brasil um campo de ação profissional direcionado a promover a difusão do conhecimento a ser aplicado em todos os âmbitos intelectuais e operacionais e, simultaneamente, a constituir-se como um campo de construção de conhecimento teórico a partir de sua empiria. Esse campo, nominalmente designado Biblioteconomia compõe suas estruturas ou se institucionaliza como prática adotante de uma sistematização oriunda de um grupo ocupacional que, sucessivamente, agrega a objetivação. Tal objetivação se materializa na forma de ensino, na organização de instâncias políticas e na ação para a pesquisa pela apropriação de saber elaborado por outras pessoas de e em outros lugares.

Concretamente, como parte de seu andamento no contexto brasileiro, viu-se serem criados por esse grupo ocupacional espaços de operação acadêmica e de representação política e, mais tarde, houve o avanço direcionado à construção das instâncias destinadas à produção de conhecimento com maior inserção de objetos locais.

Esse andamento ao correr do século $\mathrm{XX}$, ao dar forma às estruturas da Biblioteconomia, as construiu como dezenas de lugares de ação instituídos sob diferentes, mas complementares, formas: Cursos de Graduação em Biblioteconomia; Associações de Bibliotecários; Legislação profissional; órgãos de habilitação e fiscalização do exercício profissional; Associação de Ensino; editoras de periódicos especializados etc. Cada uma dessas formas idealmente representam nódulos de uma rede cujo teor essencial é a prática profissional e a educação bibliotecária; bem como o conhecimento biblioteconômico.

No espaço construído como resultado do processo socializador de segunda ordem (BERGER; LUCKMANN, 2009) essa rede é a materialização da comunicação que enseja a superestrutura constituidora do campo da ciência da biblioteca ou biblioteconomia. A comunicação, como pressuposto da interação e esta como a objetivação do interpessoal ou do fazer junto - por consensos ou por conflitos (ELIAS, 1994) - aponta para a necessidade de se pensar num processo de "construir com o outro" (ECO; MARTINI, 2000), levando a uma concepção básica traduzível pelo nome ética.

Esse termo, que não é meramente um nominalismo, se apresenta como a síntese de uma concepção em elaboração nos dois últimos milênios, a partir do gênio civilizador grego 
(ARISTÓTELES, 1996). Ele (o termo) sugere o sujeito como se constituindo por um processo de sucessivo e continuo aperfeiçoamento interior e construindo-se por erigir continuamente o seu meio e dar um sentido aos seus detritos de consciência (FLUSSER, 2007a). Aqui está referida a capacidade de criação continua do homem no espaço que o cerca das coisas que a decorrência de sua existência indica como elemento para a sua luta voltada ao adiamento da morte (FLUSSER, 2007b).

O mesmo pensador que alcunha de detritos os produtos que a mente humana transforma ao moldar/remoldar o seu espaço, utilizando matéria que está nesse espaço é o mesmo que concebe a existência humana como esse lutar pelo adiamento da morte. Ora, esse Vilém Flusser lança mão dessas ideias num claro sentido de provocar o pensamento sobre as relações que se estabelecem entre humanos podendo ser socialmente traduzidas como um mundo das instituições, isto é, das coisas instituídas, criadas a partir do ainda não instituído ou conhecido, isto é, do nada.

No espaço institucional da biblioteconomia e da prática bibliotecária brasileiras há uma decorrência nas primeiras cinco décadas do século XX que bem confirma a aplicação da ciência da biblioteca como o conhecimento que dá suporte à prática profissional dos bibliotecários. Nas duas décadas seguintes - dos anos 1950 até o final dos anos 1960 - se estabelece no contexto social uma condição nova que promoverá a reconfiguração do espaço institucional da biblioteconomia e da prática bibliotecária exercida no Brasil. A partir desse momento, se junta um novo componente de conhecimento que leva à negação de que a ciência da biblioteca seja todo o conhecimento que dá suporte à prática profissional dos bibliotecários. Esse novo componente trata-se do que se chamava Documentação. Igualmente importado do contexto internacional ou majoritariamente europeu, tal componente serve para distinguir quem faz predominantemente a aplicação em campo da ciência da biblioteca de quem faz essa aplicação enriquecida com fragmentos de uma nova ciência.

Nas três décadas seguintes - dos anos 1970 até o final dos anos 1990 -, vai se evidenciando a reconfiguração da institucionalidade. Permanecem as instituições da ciência da biblioteca e, simultaneamente, por penetração ou acostamento vão se objetivando as instituições da nova ciência, que redefine de certa forma o que era designado Documentação, passando a predominar a Ciência da Informação. Implanta-se um Curso de Mestrado dedicado a essa nova Ciência antes mesmo que a Ciência da Biblioteca estivesse preparada para implantar Curso de Mestrado em Biblioteconomia; implanta-se a comunicação científica 
dessa Ciência (periódico especializado; eventos); instituto de pesquisa e Associação científica. Por duas dessas décadas - dos anos 1970 até certa altura dos anos 1980 - são implantados Cursos de Mestrado na Ciência da Biblioteca ou Biblioteconomia (SOUZA, 2009), já num processo de conflito objetal, que vai culminar com uma nova configuração da vivência profissional. Nesta, mantém-se a estrutura criada na primeira configuração prática bibliotecária, surpreendida com a caótica aplicação de conhecimento científico que é cada vez mais oriundo da Ciência da Informação. Os cursos de graduação em biblioteconomia tendem a ser um misto de assimilação de ciência da biblioteca e da Ciência da Informação importada mais recentemente e de fragmentos de conhecimentos de Ciência da Informação produzidos no país, mas profundamente suportados em sua elaboração por matrizes de pensamento originadas nos países economicamente centrais. Isso é fácil de perceber pelo teor dos cursos de epistemologia e história da ciência da informação, predominantemente suportados pela referência a alguns teóricos da Europa Ocidental e dos Estados Unidos da América.

\section{Perfil institucional existente}

Parte-se da compreensão factual de que há um ambiente composto por entidades instituídas pelo voluntariado profissional e por ele geridas ou instituídas pelo Estado que, integrado por especialistas oriundos da Biblioteconomia e Ciência da Informação, tem nesses funcionários os prepostos adequados à sua gestão. Essas entidades, por si mesmas, dão o caráter de existência, permanência e abrigo à Biblioteconomia e à Ciência da Informação. Todas se constituíram ao longo do século XX e são formadas por indivíduos portadores de funções sociais a ela consonantes, isto é, profissionais docentes, discentes, técnicos e pesquisadores; além desses, elas contam com outros meios não menos instituídos: recursos materiais, normas e regulamentos, planejamento e execução orçamentária e de serviços, etc. Funcionam com regimes próprios de comunicação e de interação com outras instituições da sociedade brasileira, tendo em vista à produção de respostas que justifiquem o custo econômico de sua implementação no espaço social. Evidentemente, são entidades que se distinguem de quaisquer outras pela missão final própria que as constituiu.

Situar aqui o início do ano de 2014 como o momento em que se faz esta reflexão serve para se afirmar que as bases materiais sob as quais o mundo vivido da Biblioteconomia e da Ciência da Informação foi instituído no Brasil requer que também se elenque indicadores quali quantitativos nesta seção do artigo. Esses indicadores coincidem em qualidade com os 
elementos instituídos como infraestrutura da ação intencional dos agentes envolvidos com as ações e são qualitativamente: Cursos de Graduação em Biblioteconomia; Associações de Bibliotecários; Legislação profissional; órgãos de habilitação e fiscalização do exercício profissional; Associação de Ensino; editoras de periódicos especializados; eventos profissionais e científicos; instituto de pesquisa e Associação científica de ciência da informação. Quantitativamente, eles totalizam o número de entidades operantes em diferentes lugares do território brasileiro e sua relação com os fatores de demanda de sua ação.

Destacam-se dentre todas as entidades que compõem a representação política e de certificação profissional dos bibliotecários e dos cientistas da informação, isto é, as entidades constituídas como Associações de Bibliotecários que tem a Federação Brasileira de Associações de Bibliotecários, Cientistas da Informação e Instituições - FEBAB como entidade aglutinadora; Associação Brasileira de Ensino em Ciência da Informação - ABECIN - aglutinadora das Escolas ou Cursos de Biblioteconomia e respectivos docentes; Associação Nacional de Pesquisa e Pós-graduação em Ciência da Informação e Biblioteconomia ANCIB, aglutinadora dos Programas de Pós- graduação em Ciência da Informação e seus respectivos docentes/pesquisadores e, também, o Conselho Federal de Biblioteconomia CFB como entidade líder do Sistema CFB/CRB (Conselho Regional de Biblioteconomia, representando 15 unidades regionais).

As entidades: ABECIN, ANCIB, CFB e FEBAB por sua ação coordenadora foram consultadas nas pessoas de seus presidentes sobre a viabilidade de se dar início a um processo de discussão que focalizasse análise, debate e síntese de suas operações e que pudesse resultar em deliberações destinadas a superar o distanciamento sob o qual aparentemente viviam.

Um pequeno grupo de pesquisadores integrados ao GT6 da ANCIB - Informação, Educação e Trabalho - aproveitando a oportunidade propiciada nos eventos ou em visitas a outros Programas de Pós-graduação, distintos daqueles em que têm vínculo, iniciaram conversações em torno da proposição de estratégias para reunir num primeiro momento os representantes dessas entidades em janelas de programação do Grupo por ocasião da realização das edições do Encontro Nacional de Pesquisa em Ciência da Informação ENANCIB.

A primeira proposição foi apresentada aos presidentes da ABECIN, ANCIB, CFB e FEBAB, no ano de 2009, precedendo ao X ENANCIB que ocorreria na cidade de João Pessoa - PB, de 25 a 28 de outubro de 2009. Na oportunidade, as quatro entidades participaram de 
uma programação cujo tema foi: "As condições de fortalecimento e interconexões das entidades de organização científica e profissional vinculadas à Ciência da Informação no Brasil".

\section{A proposta constituidora do Fórum}

Neste ponto, se expõe sobre a preparação e o andamento dessa primeira discussão, seguindo-lhe uma explanação das condições construídas para levar à constituição e desenvolvimento do Fórum EBCIB.

Pela metade do ano de 2009, algumas conversas foram sendo realizadas informalmente, envolvendo membros do GT6 - ANCIB e dirigentes de algumas entidades voltadas à defesa e/ou promoção dos bibliotecários e outros profissionais atuantes nas áreas correlatas. Mas a percepção mais clara era de que um problema que parecia mais forte dizia respeito a certo afastamento entre as entidades o que propiciava a fragilização de todas. $\mathrm{E}$ a ideia buscada era de por onde começar a agir, uma vez que no GT6 - ANCIB, os pesquisadores, tinham algo a ver com essa discussão, na medida em que alguns deles percebiam essa questão. Decidiu-se começar pelo ambiente mais próximo, isto é, pelas entidades da Biblioteconomia e Ciência da Informação, o espaço problematizável mais tradicional.

Para dar andamento a isso, a coordenação do GT6 - ANCIB à altura, concordou em coassinar o convite às entidades. A carta convite foi formulada e remetida aos dirigentes das entidades para a primeira reunião. $\mathrm{Na}$ carta, foi dado o contexto e exposto o desafio pretendido. Ela contém a origem da proposta, a razão pela qual surgiu no âmbito do GT6 da ANCIB, a referência ao tema adotado e a forma de trabalho que seria incrementada a fim de otimizar o uso do tempo, uma vez que foram dadas duas horas da agenda do GT6 para a atividade. Nessas duas horas, que ao final foram quase três horas, pretendia-se que cada dirigente ou representante fizesse:

\footnotetext{
"uma exposição oral de sua entidade, de cerca de 20 minutos. Nela poderia ser apresentado o perfil da entidade, seus objetivos e as questões operacionais. Um destaque poderia ser dado para as dificuldades que poderiam ser superadas através de um trabalho colaborativo".
}

A essa primeira reunião compareceram como dirigentes ou representantes das entidades: Edilene Maria da Silva - Diretora Regional Nordeste da Federação Brasileira de 
Associações de Bibliotecários, Cientistas da Informação e Instituições - FEBAB, representando a Presidente Sigrid Karin Weiss Dutra; Nêmora Arlindo Rodrigues - Presidente e Célia Simonetti Barbalho $-2^{\text {a }}$. Secretaria e Coordenadora da Comissão de Cadastro de Profissionais e de Bibliotecas do Conselho Federal de Biblioteconomia - CFB; Lidia Maria Batista Brandão Toutain - Presidente da Associação Brasileira de Educação em Ciência da Informação - ABECIN e Joana Coeli Ribeiro Garcia - Presidente e Maria das Graças Targino - Secretaria Geral da Associação Nacional de Pesquisa e Pós-Graduação em Ciência da Informação - ANCIB.

O registro dessa reunião permite observar que o sentido ético de construir com o outro esteve presente no conjunto das manifestações a partir desse momento inicial.

\begin{abstract}
Falando em nome da FEBAB, Edilene Maria da Silva afirmou que a entidade está disposta a participar de iniciativas que levem ao fortalecimento coletivo. Destacou motivos que podem estar contribuindo para o enfraquecimento institucional, acentuando que o modelo atual em que os membros das diretorias fazem essa atuação como trabalho voluntário pode ser um deles [...]. Nêmora Arlindo, ao falar pelo $\mathrm{CFB}$, destacou a importância desta reunião programada no âmbito do $\mathrm{X}$ ENANCIB. Afirmou que a participação dos membros da diretoria dos Conselhos também se dá de forma voluntária, dependendo da disponibilidade pessoal. Acentuou que no atual plano de trabalho do Sistema CFB/CRBs está inclusa a aproximação com as demais entidades que atuam no âmbito da Biblioteconomia [...]. Também falando pelo CFB, Célia Barbalho agradeceu a iniciativa do GT6. Afirmou que o CFB já pensava em fazer algo semelhante a fim de apresentar e discutir a ideia de criação de um "Observatório da Profissão", análogo ao que existe em Portugal [...]. Em seguida, Lidia Brandão ao falar pela ABECIN lembrou que a ideia deste encontro que ora se realiza advém de conversa [...], na UFBA e na UNIRIO e que a grande motivação é trabalhar a fim de que se assegure a organização e manutenção da memória das Associações, pois há perda de parte da memória documental, decorrente das dificuldades operacionais de algumas entidades [...]. Pela ANCIB, Joana iniciou afirmando que foi bom poder perceber que as dificuldades da ANCIB são as mesmas que ocorrem às outras entidades presentes. Mencionou as dificuldades de ordem burocrática, que implicam a relação com cartórios, receita federal e bancos, por exemplo, e dificuldades operacionais que se refletem no site da entidade por falta de meios para o pagamento de um web designer. Mas que dá para se reconhecer que mesmo assim as atividades da ANCIB vêm sendo cumpridas, referindo-se que nos vinte anos da Associação foram realizadas dez edições do ENANCIB."
\end{abstract}

Ao longo das preleções dos dirigentes ou representantes, bem como das manifestações de mais de vinte pesquisadores presentes, membros de diferentes GTs da ANCIB, foram tirados vários encaminhamentos focando temáticas que representam problemas a serem explorados num processo de continuidade da discussão que envolve a reflexão sobre os caminhos para fortalecer as entidades e seus filiados com o fim de melhor atender à sociedade.

De acordo com os registros desta reunião, 
Os encaminhamentos apresentados versaram sobre: 1 - Viabilização da inclusão dos alunos de cursos de graduação em Biblioteconomia nas entidades representativas, assim como assegurar-se sua participação nos eventos sem o ônus para os mesmos de custo de inscrição; 2 - Criação de um centro de documentação no Conselho Federal de Biblioteconomia que tenha como missão a reunião e manutenção da memória da profissão no país; 3 - Fortalecimento das instituições e de sua relação segundo um processo que considere três eixos: a) operacional, que possa contemplar questões de ordem administrava e financeira; b) formativa, que possa articular projetos e realização de eventos, e c) documental, que assegure o resgate da memória; 4 - Diagnóstico de problemas que afetam as entidades e encontro de caminhos para a sua solução; 5 - Desenvolvimento de pesquisas que cubram as questões da área, possibilitando a implantação de inovações no ensino; 6 - Inserção na grade de programação dos eventos da ANCIB de espaço a ser utilizado pela ABECIN, de modo a com isso favorecer a participação dos alunos de graduação, pois nesse âmbito se desenvolve a pesquisa através de grupos PET, iniciação científica, etc.; 7 - Adoção de um único endereço que serviria como local de recepção e emissão de material de todas as associações da área; 8 - Reivindicação junto às agências de fomento de linha de recursos para investimento em pesquisas de interesse da área, reforçando a continuidade da atuação de um observatório da profissão sob a ótica do mercado de trabalho; 9 - Articulação de acordos formais entre as entidades, de modo que suas ações de fortalecimento e interconexão tenham o amparo de convênios entre si, assegurando continuidade; 10 - Viabilização do envolvimento de pesquisadores das várias áreas temáticas da Ciência da Informação, de modo a reforçar as ações integradas e as conexões entre as entidades.

Ainda conforme os registros dessa reunião, consignados em ata própria:

Após essa significativa série de sugestões [...] foi unânime a manifestação do sentimento de aprovação pela continuidade do esforço então iniciado, tomado como um momento histórico para a área. Disso, resultou a manifestação exposta no âmbito de representantes das entidades e aceita por todos de que se poderia dar como viável a ideia do estabelecimento de um FÓRUM DE FORTALECIMENTO E INTERCONEXÃO DAS ENTIDADES DE ORGANIZAÇÃO CIENTÍFICA E PROFISSIONAL VINCULADAS À CIÊNCIA DA INFORMAÇÃO NO BRASIL.

Assim, em 28 de outubro de 2009, na cidade de João Pessoa, PB, campus da UFPB, por ocasião do X ENANCIB foi constituído o FÓRUM DAS ENTIDADES.

\section{Desdobramentos da Constituição do Fórum}

A ideia mais central em torno da criação do Fórum EBCIB estribava-se na articulação de um espaço para discussão, deliberação e assunção dos encaminhamentos pela entidade cujo tema fosse de sua principal alçada. Nesse sentido, o esforço fundamental do Fórum é a realização da aproximação de entidades e não que ele próprio venha a ser uma nova entidade com forma jurídica e encargos fiscais semelhantes às já existentes. No caso de implantação de nova entidade, pressupôs-se que poderia ocorrer o distanciamento do compromisso básico, isto é, a articulação. Passaria a existir um propósito concorrencial, pela dependência de constituir um quadro social de contribuintes financeiros.

InCID: R. Ci. Inf. e Doc., Ribeirão Preto, v. 5, n. 2, p. 51-70, set. 2014/fev. 2015. 
De outro lado, imaginou-se que um espaço de discussão parecia atender de forma mais efetiva a noção de compromisso; algo que partindo da concepção de ação voluntária melhor se aproximaria da obrigação moralmente constituída. Nenhuma das entidades "obrigaria" a qualquer outra a participar, mas a percepção do benefício mútuo as obrigaria per si, por um sentimento que afloraria de dentro de cada uma das diretorias e associados.

Traduzindo esse sentimento para a prática, a então presidente da ABECIN tomou a iniciativa de, ainda nos últimos meses de 2009, contatar às demais dirigentes das outras três entidades para consultar e indicar o coordenador das ações a serem implementadas, conforme deliberado na reunião em João Pessoa no âmbito do Fórum. Essa indicação provisoriamente recaiu no autor deste artigo. Com isso, o ano de 2010 já se iniciou com o conhecimento de quem atenderia ao andamento das ações do Fórum EBCIB.

Em 2010, foram promovidas algumas ações. A primeira delas visava fomentar a construção de um processo de reflexão que culminaria com um planejamento conjunto das entidades. Para isso, fora solicitado "que até 25 de fevereiro de 2010 cada uma das entidades elaborasse uma breve nota de até duas páginas, sobre "que ações em comum visando ao fortalecimento e interconexões" tinha em mente, considerando quatro itens chaves: 1 - Que oportunidades o contexto nos oferece? 2 - Que ameaças o contexto nos apresenta? 3 - Quais os pontos fortes que temos e que dependem de nós próprios acioná-los? 4 - Quais os pontos fracos que temos e cuja superação dependem da articulação do que existe no contexto como oportunidades e daquilo que já contamos como pontos fortes? Esse exercício, certamente, daria um ponto de convergência, visando à construção de um sentido de coletividade institucional. A esse tópico, a ANCIB foi a única entidade que correspondeu objetiva e prontamente, enviando um documento com destaque para cada um dos itens chaves, visando o início do planejamento do Fórum. A FEBAB e a própria ABECIN justificaram-se quanto ao não retorno e o CFB mantinha sua dinâmica própria de ação institucional, conforme afirmado na primeira reunião.

Nesse ano, foi programada no âmbito do GT6-ANCIB, para realização no dia 27 outubro, a partir das 15 horas, na UNIRIO, a 2 . Reunião "As condições de fortalecimento e interconexões das entidades de organização científica e profissional vinculadas à Ciência da Informação no Brasil". A essa reunião compareceram dirigentes e representantes das entidades: Joana Coeli Ribeiro Garcia, presidente da ANCIB (UFPB); Nêmora Arlindo Rodrigues, presidente do Conselho Federal de Biblioteconomia; Célia Barbalho, $2^{\mathrm{a}}$ secretária 
do CFB; Maria Lourdes Blatt Ohira, Diretora de Promoção de Eventos da FEBAB; Oswaldo Francisco de Almeida Jr., Presidente eleito da ABECIN; Isa Maria Freire, UFPB, Candidata a Presidência da ANCIB; e mais de vinte pesquisadores de distintos GTs da ANCIB.

A coordenação da reunião suscitou a reflexão a partir dos itens chaves do planejamento estratégico do FÓRUM DAS ENTIDADES a ser formulado coletivamente, solicitando a manifestação dos dirigentes ou representantes presentes.

\begin{abstract}
Joana Coeli Ribeiro Garcia, presidente da ANCIB, relatou: como oportunidades: a iniciativa da reunião; o compromisso assumido pelo GT6 que reservou espaço para o encontro; a existência de muitos órgãos de classe; a existência de alguns órgãos com infraestrutura satisfatória e sede, o que significa chances de apoio entre as instituições; o número elevado de cursos de Biblioteconomia, Arquivologia e Museologia e de pós-graduação na área. Como pontos fortes salientou a conscientização da importância do fortalecimento e interconexões das entidades; o cumprimento de compromissos formais para pensar a área como um todo; o fortalecimento do apoio entre instituições; o entrosamento maior entre os cursos de graduação e de pós-graduação; a possibilidade de investimento em editoração; esforços para aproveitar as potencialidades oferecidas pelo CNPq, como bolsas de apoio técnico; o acompanhamento sistemático da atuação dos representantes de área no CNPq e CAPES" [...]. Como ameaças referiu-se ao baixo número de associados o que produz uma baixa receita financeira proveniente de anuidades. Nesse mesmo aspecto considerou que uma dificuldade de maior envolvimento decorre da dispersão geográfica dos Cursos e pesquisadores. A presidente do Conselho Federal de Biblioteconomia, Nêmora Arlindo Rodrigues fez um relato das ações realizadas, referindo ao processo de criação de repositório institucional do Sistema CFB/CRB, alertou para a necessidade de união de esforços, pois vê o momento como crítico pois há duas ameaças perceptíveis: uma diz respeito à possibilidade de desregulamentação da profissão, que tem origem em setores do Governo, com apoio da Confederação Nacional das Profissões Liberais (CNPL) e dos sindicatos e a outra relacionada ao baixo envolvimento dos pares. Menciona a confiança nos pares, sobretudo na ABECIN e na ANCIB para que se realize uma parceria em defesa da profissão [...]. Maria Lourdes Blatt Ohira, Diretora de Promoção de Eventos da FEBAB, falando em nome dessa entidade fez um balanço das ações realizadas em decorrência desse processo. Refere-se à realização de Assembleia em que compareceram representantes de dez Associações de Bibliotecários; que as associações têm em média cinquenta associados; que há um distanciamento entre Associações; Cursos de Biblioteconomia e professores e alunos desses cursos; que a oferta de cursos de curta duração pela FEBAB representa quase a única fonte financeira da entidade [...]. Da atual gestão da ABECIN não estava presente nenhum representante. Desse modo, [...] o presidente recém-eleito da entidade [...] teceu um breve discurso em torno da disposição da nova diretoria em dar andamento aos esforços de interconexão e tão logo a nova diretoria assuma seus encargos poderá melhor se inteirar do que será necessário realizar.
\end{abstract}

$\mathrm{Na}$ etapa de encerramento da reunião, mantendo-se a expectativa de construção coletiva do trabalho, acentuando-se o propósito deste esforço como dinâmica interacional em que os resultados serão compostos segundo as possibilidades de envolvimento e discussão inter e entre entidades, foram apresentados dois entendimentos: 1 - de que o Fórum EBCIB estaria ultrapassando os limites que permitiria seu acolhimento dentro da programação do GT6 - ANCIB, podendo ser acolhido pelo ENANCIB; 2 - de que ele deveria ser coordenado 
por uma Comissão representativa das entidades. De acordo com os registros tomados e consignados na ata:

Considerando o quadro exposto, [...] teve início a exposição de algumas propostas.
[...] Uma sugestão adicional foi de que no primeiro dia do ENANCIB quando são
realizadas as reuniões de encontros dos Coordenadores de GTs e de Pós-Graduação
também seja realizado este FÓRUM DAS ENTIDADES. Não houve discordâncias
quanto a este encaminhamento. O coordenador da reunião sugeriu que a próxima
reunião seja ainda de cunho organizativo, sucedendo à reunião a ser realizada por
ocasião do próximo CBBD, de forma que o grupo seja formalmente constituído.
Mencionou também a necessidade de se criar uma Comissão que leve à frente os
trabalhos do FÓRUM, com um representante de cada entidade. Na ocasião houve
manifestações de que permanecesse na condução da presidência da coordenação das
atividades. Sua contraproposta foi de que se indicado por uma entidade colocaria seu
nome à disposição, mas num sistema de presidência rotativa de um ano, no que
poderia ser o primeiro. Na oportunidade, seu nome foi lançado como representante
da ABECIN. O coletivo assumiu o compromisso de apontar nos próximos quinze
(15) dias os nomes dos demais representantes para compor a referida Comissão. O
Coordenador consultou se o CFB poderia disponibilizar por meio eletrônico para os
participantes a proposta do OBSERVATÓRIO DA PROFISSÃO da qual recebera a
versão impressa. A resposta [...] foi positiva.

O ano de 2011 iniciou-se com uma Comissão do FÓRUM DAS ENTIDADES composta apenas pelo representante da ABECIN e pela representante do CFB. ANCIB e FEBAB participariam das atividades programadas através de sua presidência e/ou de representante ad hoc.

Nesse ano, foi lançado em ambiente eletrônico o Grupo Forum: Entidades Ciencia da Informação: Brasil (https://groups.google.com/group/forum-entidades-ciencia-da-informacaobrasil?hl=pt-BR), visando ancorar a discussão e permuta de informações sobre o andamento das ações do Fórum; por ser realizado através de um canal de comunicação online, supôs-se que ele seria capaz de assegurar o fácil acesso aos interessados.

Quando da realização do XXIV CBBD, em agosto de 2011, foi promovida pelo CFB com a presença das demais entidades uma reunião, na qual se deliberou sobre a constituição de um movimento denominado PACTO PELA BIBLIOTECONOMIA BRASILEIRA, cujos desdobramentos envolveriam a participação das entidades na discussão de alguns encaminhamentos a fim de fortalecer o trabalho até então desenvolvido.

Em 2011 foi realizada a $3^{\mathrm{a}}$. Reunião do FÓRUM DAS ENTIDADES, a fim de dar continuidade ao tema global: "As condições de fortalecimento e interconexões das entidades de organização científica e profissional vinculadas à Ciência da Informação no Brasil”. Essa atividade aconteceu no âmbito do XII ENANCIB, realizado de 23 a 26 de outubro. A reunião em si aconteceu no dia 25 de outubro, a partir das 18 horas, na Faculdade de Ciência da 
Informação da UNB. Para essa reunião os convites foram também destinados a outras entidades, entre elas três sindicatos de bibliotecários dos quais foram obtidos os endereços. Entretanto algumas dessas entidades não se fizeram representar. Dirigentes ou representantes presentes: Tatiana de Souza Martins, Presidente do Sindicato dos Bibliotecários no Estado do Rio de Janeiro; Oswaldo Francisco de Almeida Junior, Presidente da Associação Brasileira de Ensino em Ciência da Informação - ABECIN; Isa Freire, Presidente da Associação Nacional de Pesquisa em Ciência da Informação - ANCIB; Nêmora Arlindo, Presidente do Conselho Federal de Biblioteconomia; Isa Antunes de Araújo, Presidente da Associação de Bibliotecários do Distrito Federal - ABDF, representando a Presidente da Federação Brasileira de Associações de Bibliotecários - FEBAB. Também estiveram presentes: Thalita Franco dos Santos, Presidente da Associação dos Bibliotecários de Goiás- ABG, Célia Maria Escobar Araújo, Representante do Grupo de Bibliotecários de Informação e Documentação Jurídica do Estado do Rio de Janeiro - GIDJ/RJ, Maria Elizabeth B. C. de Albuquerque, membro da diretoria do CFB e Sueli Bortolin, membro da diretoria da ABECIN. Após uma ampla rodada de discussões, concluiu-se o encontro com os seguintes encaminhamentos: aAceitação da proposta trazida pela ABECIN de dar ao Fórum o caráter de parlamento político composto pelos dirigentes das entidades; $b$ - Acolhimento da proposição da representação do CFB de que a equipe jurídica do órgão poderá preparar uma minuta de Termo de Colaboração entre as entidades, visando oferecer continuidade às ações já desencadeadas; c - Proposição pela Coordenação da reunião e aceita pelos presentes, particularmente, pela representação do $\mathrm{CFB}$, de que esta entidade oferecerá às demais entidades participantes deste Fórum, a ser programada para realização até o mês de março de 2012, na cidade de Brasília, uma oficina de capacitação na tecnologia de organização desenvolvida pelo Conselho Federal de Biblioteconomia a fim de estabelecer seu planejamento estratégico. Essa deliberação gerou sentimento de uma conquista futura de fortalecimento das entidades pela perspectiva de se constituir um discurso comum quanto a estratégias de ação mais consensuais; d - Com relação à Coordenação interentidades não houve decisão, permanecendo a situação então existente até que se tomasse uma decisão definitiva por ocasião da oficina de capacitação na tecnologia de organização.

O ano de 2012 apontou para novos desafios a serem superados tanto referentes ao contexto em que atuam as entidades, quanto em sua percepção do sentido que o FÓRUM poderia ter para o desempenho de suas missões.

InCID: R. Ci. Inf. e Doc., Ribeirão Preto, v. 5, n. 2, p. 51-70, set. 2014/fev. 2015. 
Nesse ano, conforme acordado na $3^{\mathrm{a}}$ reunião do FÓRUM DAS ENTIDADES, foram realizados dois encontros de trabalho técnico, em março e em maio. Neles estiveram presentes dirigentes e/ou representantes das quatro entidades então participantes do FÓRUM (ABECIN, ANCIB, CFB, FEBAB). Essas reuniões ocorreram na sede do CFB, em Brasília, e para elas o CFB cedeu todas as condições materiais de trabalho e ofertou algumas passagens aéreas, para favorecer o deslocamento e a participação de membros das outras entidades. Nessas reuniões, buscou-se construir através da metodologia SWOT, dinamizada pela Profa. Célia Simonetti Barbalho, um levantamento sobre os PONTOS FORTES e FRACOS; OPORTUNIDADES e AMEAÇAS relativos a cada entidade para, a partir disso, chegar-se a uma percepção de como o contexto brasileiro os replica sobre o FÓRUM, isto é, no conjunto das entidades vistas como uma unidade de objetivo e missão. Uma síntese desse trabalho está disponível em vídeo no youtube, podendo ali ser localizado pelo termo "Fórum EBCIB", em https://www.youtube.com/watch?v=D3Bd42ZE8Z8, ou buscado no perfil "Fórum EBCIB", através do Facebook.

Esse investimento feito pelo CFB expressa a confiança no trabalho coletivo do FÓRUM. Paralelo ao CFB, a ANCIB assegurou espaço no ENANCIB para a realização das reuniões e ofereceu apoio material à presença da coordenação do mesmo para o desenvolvimento das reuniões de Brasília (2011) e Rio de Janeiro (2012).

Ainda em 2012, com a finalidade de ampliar o acesso da sociedade ao FÓRUM, chamado desde então de FÓRUM EBCIB, como estratégia de simplificação nominal, foi lançado um perfil de Grupo - FÓRUM EBCIB - no Facebook, disponível em: <http://www.facebook.com/groups/390478521013668/>. Igualmente, foi lançado um blog em: <http://f-ebcib.blogspot.com.br/2012/07/breve-historico-do-forum-o-forum-das.html>.

A posse desses canais, seu potencial de atração e disseminação de propostas e o sucesso dessas ações estão diretamente relacionados com o próprio esforço das entidades em torná-los fortes. Uma forma de fazer tal reforço, viria com a inserção de seus links nas homepages das entidades ou, ao contrário, com seu uso como espaço complementar daquelas para divulgações. O que tem acontecido é que esse esforço não foi claramente fortalecido.

Ainda no ano de 2012, o FÓRUM EBCIB produziu e o CFB fez o devido encaminhamento de dois documentos junto aos respectivos destinatários. Um tratou-se de manifestação formal anexada ao projeto de Lei 28/2012, que tramitava no Senado Federal, defendendo a não aprovação de tal projeto na forma em que encontrava por ser danosa aos 
interesses dos profissionais bibliotecários. O outro se tratou de manifestação para a Ministra titular do Ministério da Cultura, alertando para a necessidade de ampliação de investimentos no setor de bibliotecas públicas e Biblioteca Nacional.

Nesse ano, foi realizada no dia 29 de outubro a $4^{\mathrm{a}}$ reunião do FÓRUM, por ocasião do XIII ENANCIB, que se deu Centro de Convenções Sul America, na cidade do Rio de Janeiro - RJ, a partir das 17 horas. A ela compareceram os dirigentes e ou representantes das entidades e mais de vinte pesquisadores de distintos GTs da ANCIB. Wagner Ridolphi AAERJ - ENARA; Sigrid Karin Weiss Dutra - FEBAB; Oswaldo Francisco de Almeida Junior - ABECIN; Miriam de F. Cruz - SINDIB; Tatiana de Souza Martins - SINDIB-RJ; Luciana Pinhel - SINDIB-RJ; Claudia Aragon - REDARTE-RJ; Miguel R. Amorim Neto CRB7; Célia Maria Escobar Araújo - GIDJ/RJ; Sandra R. S. Benigno - APCIS/RJ; Nêmora Arlindo - CFB; Vania Ap. Bari - APBDSE; Isa Freire - ANCIB. A nominata das entidades presentes revelou o fato de que o atendimento ao convite por parte delas fortaleceu a percepção do potencial de mobilização que o FÓRUM EBCIB poderia proporcionar.

Durante a reunião, considerando a presença de novas entidades, foi feito o relato e discussão das ações já realizadas pelas entidades e origem (CFB, ANCIB, ABECIN e FEBAB) e pelo FÓRUM, nesses últimos anos. Pelo CFB, Nêmora Arlindo, ressaltou o trabalho de organização e planejamento realizado pelo Conselho nas duas últimas gestões. Deu destaque ao esforço realizado em torno do Pacto pela Biblioteconomia no Brasil e os resultados que vêm sendo alcançados; b) pela ANCIB, Isa Freire, deu destaque à conexão existente entre o trabalho realizado pela entidade que dirige e o trabalho feito pelas demais; c) pela ABECIN, Oswaldo Almeida Jr., destacou sua experiência como membro de várias outras entidades, ao longo de sua careira profissional e lembrando as dificuldades existentes em torno do movimento associativo, sobretudo quando lidou com o processo de criação do Sindicato dos Bibliotecários do Estado de São Paulo; d) pela FEBAB, Sigrid Dutra, referiu-se aos esforços empreendidos pela Federação nos últimos dois anos na manutenção de suas atividades e a busca por vencer alguns contratempos financeiros que quase colocaram em risco seu patrimônio: as duas salas legadas à entidade por Laura Russo. Mencionou que, no momento, a FEBAB superou as dificuldades financeiras e está buscando o restabelecimento de um fluxo mais dinâmico de atividade e ampliação de sua participação e representatividade, inclusive no Fórum das Entidades; e) pelo FÓRUM, Francisco das Chagas de Souza, discorreu sobre Ações realizadas em 2012. 
Também foram discutidas as possibilidades de ampliação institucional do FÓRUM, com a participação de novas entidades. As manifestações nesse tópico foram feitas pelas entidades convidadas. AAERJ, através de Wagner Ridolphi; SINDIB-RJ, através de Tatiana de Souza Martins; REDARTE-RJ, através de Cláudia Aragon; GIDJ-RJ, através de Celia Escobar Araújo e APCIS-RJ, através de Sandra Benigno. De forma geral, houve manifestação de interesse na participação, mas alguma apreensão quanto às possibilidades de assunção de encargos materiais-financeiros, tendo em vista as limitações estruturais com que essas entidades convivem. De outro lado, nenhum dos representantes negou o potencial de aplicação das estratégias que já conhecem quanto à busca e obtenção de meios que favoreçam a execução de reuniões de trabalho.

Outro aspecto abordado foi a definição do local e da estrutura para a realização da V Reunião do FÓRUM. Não se abriu mão de sua possível inserção no próximo ENANCIB, a acontecer em Florianópolis, em 2013. Entretanto, fez-se uma discussão sobre outras possibilidades de locais para a sua realização. Pela FEBAB, Sigrid Dutra colocou o próximo CBBD, a realizar-se no mês de julho de 2013 em Florianópolis, SC, como um abrigo à próxima reunião do FÓRUM EBCIB; Zeny Duarte (UFBA) anunciou para 2013 a realização de evento em Salvador, BA, que reuniria as três áreas: Arquivologia, Biblioteconomia e Museologia, afirmando que nele poderia ser aberta uma janela na programação para que o FÓRUM pudesse estar presente; Wagner Ridolphi - AAERJ também apresentou a possibilidade de abertura de uma janela na programação de evento de Arquivologia a ser realizado no Rio de Janeiro em 2013, para que o FÓRUM pudesse estar presente. Essas manifestações suscitaram o comentário apropriado de que ao ter agenda o FÓRUM passava a dispor de espaço para reunião e manifestação e que isso poderia ser um bom sinal em relação à construção de uma proposta comum que pudesse ser apresentada em 2014 aos candidatos à próxima eleição presidencial no Brasil.

Favorecer as interações entre as entidades da Biblioteconomia e Ciência da Informação, e demais organizações correlacionadas, e chegar a um estágio de consenso traduzível em proposta comum de uma comunidade de profissionais que atuam e têm como objeto a informação, podendo pautar uma questão fundamental na discussão nacional, é uma referência mobilizadora do FÓRUM EBCIB. Naquele momento de 2012 isso foi suscitado.

Parece evidente que a aposta em torno do comando ético "construir com o outro" requer paciência e respeito às dinâmicas institucionais das entidades parceiras. De outro lado, 
exige a consideração de um momento histórico em que, no Brasil, se está buscando encontrar ou reencontrar caminhos mais generosos para a ação coletiva.

O material textual oriundo das atas das reuniões do Fórum, transcrito nas seções anteriores deste artigo mostra que passos foram dados e quais foram os ganhos obtidos. Porém, essa dinâmica requer uma assimilação que leve à formação de uma cultura de valorização do coletivo interinstitucional. Pensar sobre isso, quer dizer, sobre a dinâmica da construção com o outro é o ponto de partida e de andamento desta proposta.

\section{Dificuldades a vencer ou Considerações finais}

O FÓRUM EBCIB reflete o seu contexto sócio e cultural e as características das entidades que ele tem como meta colocar em interação sistemática. Ações isoladas e descontínuas, certas desconfianças com o trabalho coletivo, personalização e permanência de dirigentes por falta de concorrentes à alternância das diretorias não são fenômenos desconhecidos. E por essa via, surgiram alguns obstáculos a serem superados pelo FÓRUM, caso as manifestações sobre sua relevância tenham o sentido até agora dado.

a) Personalismo. O FÓRUM EBCIB não poderia ser vinculado a pessoas, mas às entidades. E esse foi o entendimento dos membros de sua Comissão Executiva.

$\mathrm{Na} 4^{\mathrm{a}}$ reunião, realizada em 2012, foi anunciado aos presentes que a ABECIN, atendendo ao pedido de seu então representante levou e discutiu em reunião a substituição desse pelo Professor Carlos Alberto Ávila de Araújo, UFMG, como seu novo representante no FÓRUM. De igual maneira, o CFB, que passaria a ter nova diretoria a ser empossada em dezembro de 2012, indicaria nome para substituir a Professora Célia Simonetti Barbalho, UFAM, sua então representante e assim também o faria a ANCIB, que no momento estava representada nessa Comissão por sua própria presidente.

b) Isolacionismo. O FÓRUM EBCIB deverá se efetivar como um parlamento dos dirigentes das entidades que o compõem.

Essa decisão foi aprovada em 2011, na $3^{\text {a }}$ reunião do FÓRUM. Sem prejuízo da funcionalidade representada por uma Comissão Executiva, os dirigentes das Entidades teriam no FÓRUM um espaço comum para construírem estratégias de defesa dessas entidades e de 
seus associados no âmbito da sociedade, em que o encaminhamento surtiria mais efeito quando resultado de uma construção conjunta.

c) Esvaziamento. O FÓRUM EBCIB deverá efetivar uma Comissão Executiva representativa das entidades que o integram.

Em 2010, na $2^{\text {a }}$ reunião do FÓRUM, foi decidido que haveria uma Comissão Executiva constituída por representantes das entidades que o integram. Efetivamente, apenas metade das entidades atenderam a esse compromisso. Nesse caso, há uma atitude a ser modificada. Se entre o que foi acordado e o que foi implementado há tão significativa discordância, algo há que ser feito para a efetivação das ações do FÓRUM.

d) Conflituosidade. O FÓRUM EBCIB necessita para evitar ambiguidades na sua condução de um Regimento, assim como o da FESABID - Espanha.

No ano de 1988 constituiu-se na Espanha a Federación Española de Sociedades de Archivística, Biblioteconomía, Documentación y Museística (FESABID) como uma entidade de direito privado, com a finalidade de reunir as associações profissionais mais relevantes da área de informação.

Evidentemente, a FESABID é uma federação de associações; mas é muito mais ampla que a FEBAB brasileira, pois também admite a filiação de associações de arquivistas e museólogos. Seu regimento se organiza de uma forma em que as identidades das entidades setoriais e temáticas são respeitadas; o esforço maior da integração se concentra nas questões de amplo interesse político.

Aqui se invoca o regimento por tomá-lo como instrumento relevante para resguardar a singularidade das entidades participantes em um empreendimento coletivo ainda que informal. Em outras palavras, o FÓRUM não demandaria constituir-se como mais uma entidade, por razões já apontadas, mas requer que se evite fricções e conflitos políticos internos em suas ações. Desse modo, um regimento que oriente a atuação do FÓRUM poderia ser de grande valia, com implicações operacionais e de boas práticas na conduta das questões do dia-a-dia.

Ao final da $4^{\mathrm{a}}$ reunião foi feita a ponderação no sentido de que é necessário cuidado para que a sustentação do FÓRUM, como parlamento e espaço de interlocução, não perca de vista o entrelaçamento de ações a fim de não haver prejuízo na continuidade dele. 
e) Descontinuidade. No FÓRUM EBCIB a descontinuidade das ações é hoje uma dificuldade a ser superada. No ano de 2013 não foram realizadas atividades por uma nova Comissão Executiva do FÓRUM, pois aparentemente essa não foi constituída. Seu pertencimento às entidades que o constituíram, seus canais disponíveis online, os subsídios para o planejamento estratégico, construídos nas reuniões realizadas em março e maio de 2012, em Brasília, são parte de um capital construído ao longo de pelos menos quatro anos pelos dirigentes e representantes das entidades movidos pelo sentimento de que algo deveria ser vencido, isto é, o afastamento operacional e, também, político das entidades, o que a persistir lhes enfraquece politicamente, na medida em que trabalham individualmente com o próprio esforço. E isso, certamente, constitui a essência e a razão que levaram à proposição, configuração e dinamização do FÓRUM EBCIB.

\section{Referências}

ARISTÓTELES. Ética a Nicômaco. In: Vida e obra. São Paulo: Círculo do Livro, 1996. p. 117-320.

BERGER, P. L.; LUCKMANN, T. A construção social da realidade. 30. ed. Petrópolis: Vozes, 2009.

ECO, U.; MARTINI, C. Quando o outro entra em cena, nasce a ética. In: . Em que crêem os que não crêem. Rio de Janeiro: Record, 2000.

ELIAS, N. A sociedade dos indivíduos. Rio de Janeiro: Jorge Zahar, 1994.

FEDERACIÓN ESPAÑOLA DE SOCIEDADES DE ARCHIVÍSTICA, BIBLIOTECONOMÍA, DOCUMENTACIÓN Y MUSEÍSTICA - FESABID. Disponível em: <http://www.fesabid.org/>. Acesso: 16 abr. 2014.

FLUSSER, V. Língua e realidade. São Paulo: Annablume, 2007a.

FLUSSER, V. O mundo codificado; por uma filosofia do design e da comunicação. São Paulo: Cosac Naify, 2007b.

FÓRUM EBCIB - Entidades da Biblioteconomia e Ciência da Informação no Brasil. Disponível em: $<$ https://groups.google.com/group/forum-entidades-ciencia-da-informacao-brasil?hl=pt-BR $>$. Acesso: 16 abr. 2014.

Disponível em: <https://www.youtube.com/watch?v=D3Bd42ZE8Z8>. Acesso: 16 abr. 2014. [video] 

abr. 2014

Disponível em: <http://www.facebook.com/groups/390478521013668/>. Acesso: 16

Debate permanente das temáticas relacionadas ao cotidiano das Entidades associativas de Profissionais, Educadores e Pesquisadores em Biblioteconomia, Ciência da Informação e temas correlatos no Brasil: breve histórico do fórum. Disponível em: $<$ http://f-ebcib.blogspot.com.br/2012/07/breve-historico-do-forum-o-forum-das.html $>$. Acesso em: 16 abr. 2014.

SCHUTZ, A.; LUCKMANN, T. Las estructuras del mundo de la vida. Buenos Aires: Amorrortu, 2003.

SOUZA, F. C. O ensino da biblioteconomia no contexto brasileiro: século XX. Florianópolis: EDUFSC, 2009. 